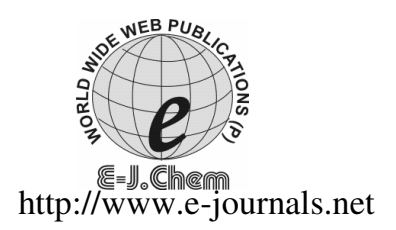

ISSN: 0973-4945; CODEN ECJHAO

E-Journal of Chemistry

2011, 8(3), 1293-1297

\title{
Studies in Asymmetric Epoxidation of Chalcone Using Quaternary Salts and Nonionic Surfactants Based on 6-Amino-6-deoxy-glucose as Chiral Phase Transfer Catalysts
}

\author{
LALIT SHARMA*, SUBHASH CHANDER SHARMA and SAROJ \\ *Department of Applied Chemistry \\ Shaheed Bhagat Singh College of Engg and Tech Ferozepur-152 004, India \\ s.lalit@lycos.com
}

Received 24 April 2010; Revised 24 September 2010; Accepted 8 January 2011

\begin{abstract}
Quaternary salts and nonionic surfactants based on 6-amino-6deoxy-glucose were explored as chiral phase transfer catalysts for the asymmetric epoxidation of chalcone. Quaternary salts used in the present study, were void of any branched chain or long hydrocarbon chain, whereas the sugar based nonionic surfactants have a long hexadecyl moiety as tail. It was observed that quaternary salts showed no activity as phase transfer catalysts but sugar based nonionic surfactants acted as chiral phase transfer catalysts. It was also revealed that hydrophilicity of the surfactant favors more yield whereas stereochemistry governs enantioselectivity. (6,6'-Hexadecylimino) bis(6-deoxy-1,2- $O$-isopropylidene- $\alpha-D$-glucofuranose) was found to be the most suitable chiral phase transfer catalyst, resulting asymmetric epoxidation of chalcone with $90 \%$ yield and $16.5 \%$ enantiomeric excess (ee).
\end{abstract}

Keywords: Asymmetric epoxidation, Chalcone, Quaternary sugar salts, Nonionic surfactants

\section{Introduction}

Although, sharpless paved the way for much of today's catalytic asymmetric syntheses ${ }^{1}$, the use of phase-transfer catalysts in asymmetric synthesis was described ${ }^{2-6}$ in the mid-1970s. Various methods, including phase transfer catalysis (PTC), for the asymmetric epoxidation of electron-deficient olefins, as particularly $\alpha, \beta$-enones, have attracted widespread attention. There are excellent reviews ${ }^{7,8}$ available on this subject. The applications of epoxy ketones as versatile building blocks in organic synthesis has also been reviewed ${ }^{9}$.

Recently, some new methods for asymmetric enone epoxidation have been reported ${ }^{10-15}$, but the possibility of using sugar based quaternary salts and nonionic surfactants as chiral 
phase transfer catalysts has not been systematically explored or generalized. The present study describes the use of quaternary salts of some 6-amino-6-deoxy- $D$-glucose derivatives and glucose based nonionic surfactants for the asymmetric epoxidation of chalcone. To our knowledge, this is first example of exploring quaternary sugar salts and sugar based nonionic surfactants as chiral phase transfer catalysts for asymmetric epoxidation of chalcone.

\section{Experimental}

Melting points were determined in capillaries and are uncorrected. ${ }^{1} \mathrm{H}$ NMR spectra were recorded at $200 \mathrm{MHz}$ on a Bruker FT NMR 200 Spectrometer. TMS was used as internal reference for solutions in deuteriochloroform. Optical rotations were measured with a JASCO DIP-360 digital polarimeter in a $1 \mathrm{dm}$ cell. Column chromatography was performed on silica gel (60-120 mesh) and TLC plates were coated with silica G. The spots were developed in iodine and / or charring with $1 \%$ sulfuric acid in water. Distilled solvents were used for column chromatography. Other chemicals were of analytical grade and used without further purification.

General procedure for asymmetric epoxidation of chalcone under phase transfer conditions

A mixture of chalcone $1(1.02 \mathrm{~g}, 5 \mathrm{mM})$ and PTC $(0.5 \mathrm{mM})$ in a biphase system, dichloromethane and $30 \%$ aqueous $\mathrm{H}_{2} \mathrm{O}_{2}(4.5 \mathrm{~mL})$ was added and stirred at $0{ }^{\circ} \mathrm{C}$ for $30 \mathrm{~min}$. Sodium hydroxide $(0.38 \mathrm{~g}, 9.5 \mathrm{mM})$ was added and mixture solution stirred at room temperature for $24 \mathrm{~h}$. On completion of reaction, yellow color had disappeared or changed to light color. Dichloromethane $(100 \mathrm{~mL})$ was added and the mixture solution washed with water $(2 \times 10 \mathrm{~mL})$. Dichloromethane layer was separated, dried over sodium sulphate and evaporated at reduced pressure. The crude material was subjected to column chromatography with hexane: dichloromethane (50:50v/v) as elutant to afford colorless solid (2), m.p. 64-65 ${ }^{\circ} \mathrm{C}$, literature ${ }^{16}$ m.p. $64-65{ }^{\circ} \mathrm{C} .{ }^{1} \mathrm{H}$ NMR $(200 \mathrm{MHz}) \delta: 4.08(\mathrm{~d}, 1 \mathrm{H}, \mathrm{J}=1.6 \mathrm{~Hz}, \mathrm{H}-$ 3); $4.30(\mathrm{~d}, 1 \mathrm{H}, \mathrm{J}=1.6 \mathrm{~Hz}, \mathrm{H}-2) ; 7.40-8.00(\mathrm{~m}, 10 \mathrm{H}$, Ar H). The specific rotation of the resulted chalcone epoxide (2), for each entry, was measured in chloroform and compared with the literature data ${ }^{17}$ to obtain enantiomeric excess (ee).

\section{(2E)-1,3-diphenylprop-2-en-1-one (chalcone) (1)}

Sodium hydroxide $(2.18 \mathrm{~g}, 54.5 \mathrm{mM})$ was added to water-ethanol mixture $(2: 1,30 \mathrm{~mL})$ and solution stirred for $5 \mathrm{~min}$. at room temperature. Acetophenone $(5.36 \mathrm{~g}, 45 \mathrm{mM})$ was added and mixture solution stirred vigorously in ice bath for $10 \mathrm{~min}$. followed by addition of benzaldehyde $(4.80 \mathrm{~g}, 45 \mathrm{mM})$. The mixture solution was further stirred for $3 \mathrm{~h}$ in ice bath. The stirring was discontinued and it was placed in ice bath for overnight. Pale yellow solid was separated by filteration with suction on a Buchner funnel and recrystallized from ethanol to afford $1(6.32 \mathrm{~g}, 72 \%)$; m.p. $56-57{ }^{\circ} \mathrm{C}$; lit. ${ }^{18}$ m.p. $57-58{ }^{\circ} \mathrm{C}$.

6-Deoxy-6-trimethylammonium-1,2-O-isopropylidene- $\alpha$-D-glucofuranoseiodide (3)

The compound was synthesized as described in literature ${ }^{19}$. m.p. $240{ }^{\circ} \mathrm{C}$ (decomp.); lit. m.p. $240{ }^{\circ} \mathrm{C}$ (decomp).

\section{6-Deoxy-6-diethylmethylammonium-1,2-O-isopropylidene- $\alpha$-D-glucofuranose iodide (4)}

The compound was synthesized as described in literature ${ }^{19}$. It was obtained as syrup.

\section{6-Deoxy-6-diethylbenzylammonium-1,2-O-isopropylidene- $\alpha$-D-glucofuranose chloride (5)}

The compound was synthesized as described in literature ${ }^{19}$. m.p. $65-66{ }^{\circ} \mathrm{C}$; lit. m.p. $64-66{ }^{\circ} \mathrm{C}$. 
6-Deoxy-6-(N-benzylhexadecyl)amino-1,2-O-isopropylidene- $\alpha$-D-glucofuranose (6)

The compound was synthesized as reported in literature ${ }^{20}$. It was subjected to column chromatography and elution with dichloromethane:ethyl acetate $(65: 35 \mathrm{v} / \mathrm{v})$ afforded $\mathbf{6}$ as colorless solid, m.p. $65^{\circ} \mathrm{C}$; lit. ${ }^{20}$ m.p. $64{ }^{\circ} \mathrm{C}$.

\section{(6,6'-Hexadecylimino)bis(6-deoxy-1,2-O-isopropylidene- $\alpha$-D-glucofuranose) (7)}

The compound was synthesized as reported in literature ${ }^{20}$. It was subjected to column chromatography and elution with dichloromethane:ethyl acetate (20:80 v/v) afforded 7 as syrup.

(6,6'-Hexadecylimino)bis(6-deoxy-D-glucopyranose) (8)

To $7(0.2 \mathrm{~g})$ in dichloromethane $(3 \mathrm{~mL})$ trifluoroacetic acid $(0.1 \mathrm{~g})$ was added and mixture solution was stirred at room temperature for $1 \mathrm{~h}$. The solvent was evaporated under reduced pressure. The product showed single spot on TLC and was further used without isolation.

\section{Results and Discussion}

The glucose derivatives (3-8) explored for asymmetric epoxidation of chalcone (1) are given in Scheme 1. Quaternary sugar salts (3-5) ${ }^{19}$ and glucose based nonionic surfactants (6-8) ${ }^{20}$ are known compounds and have already been reported by one of us. In the present study, dichloromethane was used as the organic phase and 30\% water solution of hydrogen peroxide was used as the aqueous phase. Table 1 summarizes the results.

Preliminary studies were focused on the investigation of the asymmetric epoxidation of chalcone (1) with catalytic amount $(0.5 \mathrm{mM})$ of sugar quaternary salts (3-5) of 6-amino-6deoxy- $D$-glucose derivatives. This investigation did not produce any encouraging results. There was no reaction even after $24 \mathrm{~h}$, as monitored by TLC. This happens probably because unlike normal quaternary salts used as phase transfer catalysts [e.g. tetrabutylammonium $\left.\left(\mathrm{C}_{4} \mathrm{H}_{9} \mathrm{~N}^{+}\right)\right]$, the catalysts (3-5) are void of any branched or long hydrophobic alkyl chain, thus remained unable to act as phase transfer catalysts.

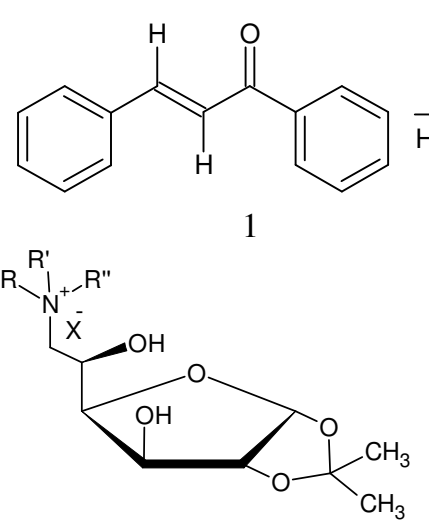

$3 \mathrm{R}=\mathrm{R}^{\prime}=\mathrm{R}^{\prime \prime}=\mathrm{CH}_{3}, \mathrm{X}=\mathrm{I}$,

$4 \mathrm{R}=\mathrm{R}^{\prime}=\mathrm{CH}_{2} \mathrm{CH}_{3}, \mathrm{R}^{\prime \prime}=\mathrm{CH}_{3}, \mathrm{X}=\mathrm{I}$,

$5 \mathrm{R}=\mathrm{R}^{\prime}=\mathrm{CH}_{2} \mathrm{CH}_{3}, \mathrm{R}^{\prime \prime}=\mathrm{CH}_{2} \mathrm{Ph}, \mathrm{X}=\mathrm{Cl}$<smiles>O=C(c1ccccc1)[C@@H]1O[C@H]1c1ccccc1</smiles>

2

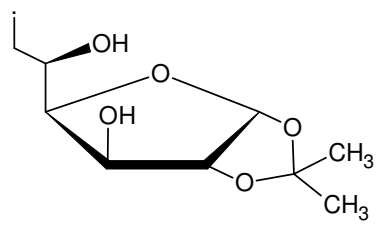

G

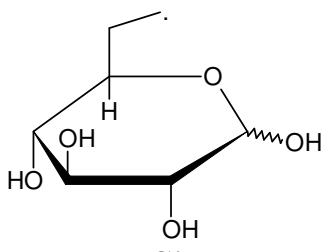

G'

$$
\begin{aligned}
\mathrm{H}_{3} \mathrm{C}-\left(\mathrm{CH}_{2}\right)_{15}-\mathrm{NRR}^{\prime} \\
\mathbf{6} \mathrm{R}=\mathrm{CH}_{2} \mathrm{Ph}, \mathrm{R}^{\prime}=\mathrm{G} \\
\mathbf{7} \mathrm{R}=\mathrm{R}^{\prime}=\mathrm{G} \\
\mathbf{8} \mathrm{R}=\mathrm{R}^{\prime}=\mathrm{G}^{\prime}
\end{aligned}
$$

\section{Scheme 1}


Table 1. The Effect of chiral PTCs 3-8 on the enantioselectivity in epoxidation of chalcone (1)

\begin{tabular}{cccc}
\hline Entry & Catalyst & Yield of $2, \%$ & ee, $\%^{\mathrm{a}}$ \\
\hline $\mathbf{a}$ & 3 & No reaction & ---- \\
$\mathbf{b}$ & 4 & No reaction & ---- \\
$\mathbf{c}$ & 5 & No reaction & --- \\
$\mathbf{d}$ & 6 & 78 & 9.4 \\
$\mathbf{e}$ & 7 & 86 & 16.5 \\
$\mathbf{f}$ & 8 & 90 & 12.3 \\
\hline
\end{tabular}

${ }^{a}$ The enantiomeric excess (ee) for each entry was determined by comparison of specific rotation for 2 with literature data ${ }^{17} ;[\alpha]_{D}{ }^{23}=-157.2\left(\mathrm{c} \mathrm{O} 0.40, \mathrm{CHCl}_{3}\right)$

The focus was then concentrated on exploring glucose based nonionic surfactants (6-8) as chiral PTCs. As expected, all the three surfactants showed promising results. The compound 6 gave $78 \%$ yield with $9.4 \%$ enantiomeric excess (ee) of the resulting chalcone epoxide, the compound 7 provided $86 \%$ epoxide with $16.5 \%$ ee and $\mathbf{8}$ afforded $90 \%$ epoxide with 12.3 ee, respectively.

Out of sugar based nonionic surfactants used here, $\mathbf{8}$ was found to be the most effective phase transfer catalyst resulting $90 \%$ of chalcone epoxide. It can be justified on the lines that sugar surfactants used in present study have hydrophilic:hydrophobic ratio in the order $\mathbf{8}>\mathbf{7}>\mathbf{6}$. It seems as if more hydrophilic: hydrophobic ratio results in better efficiency as phase transfer catalyst for each surfactant, thus $\mathbf{8}$ acts as a better shuttling agent for extracting $\mathrm{H}_{2} \mathrm{O}_{2}$ from aqueous phase into the organic reaction phase thus causing asymmetric epoxidation of chalcone in better yield compared to other surfactants used.

The better enantioselectivity achieved by using 7 as chiral phase transfer catalyst can be justified on the lines that its stereochemistry better enhances the discrimination in the oxygen transfer process, between the enantiotopic faces of the chalcone, compared to other phase transfer catalysts i.e. $\mathbf{6}$ and $\mathbf{8}$ used in this study.

The inferior yield and enantioselectivity achieved using $\mathbf{6}$ as PTC is due to being most hydrophobic, it has poor efficiency as shuttling agent for extracting $\mathrm{H}_{2} \mathrm{O}_{2}$ from aqueous phase into the organic reaction phase.

\section{Conclusion}

Quaternary sugar salts and sugar based nonionic surfactants derived from 6-amino-6-deoxyglucose were explored, for the first time, as chiral phase transfer catalysts for the asymmetric epoxidation of chalcone. It was found that quaternary sugar salts, being void of any branched or long alkyl chain, remain unable to act but sugar based nonionic surfactants with hexadecyl moiety as tail acted as chiral PTCs. It was also revealed that more hydrophilicity of the surfactant resulted in better yield of desired chalcone epoxide but enantioselectivity of the reaction was governed by the stereochemistry. The present investigation suggests that sugar based nonionic surfactants have excellent scope for further development as chiral PTCs.

\section{Acknowledgment}

This work was supported by the Department of Science and Technology, Government of India, New Delhi. 


\section{References}

1. Johnson R A and Sharpless K B, In Comprehensive Organic Synthesis, Eds., Trost B M and Fleming I, Pergamon Press, Oxford, Newyork, Seoul, Tokyo, 1991, 7, 389.

2. Colonna S and Fornasier R, Synthesis, 1975, 531.

3. Hiyama T, Sawada H, Tsukanaka M and Nozaki H, Tetrahedron Lett., 1975, 16, 3013.

4. Fiaud J C, Tetrahedron Lett., 1975, 16, 3495.

5. Hiyama T, Mishima T, Sawada H and Nozaki H, J Am Chem Soc., 1976, 98, 641.

6. Helder R, Hummelen J C, Laane R W P M, Wiering J S and Wynberg H, Tetrahedron Lett., 1976, 17, 1831.

7. Porter M J and Skidmore J, Chem Commun., 2000, 1215-1225.

8. Diez D, Nunez M G, Anton A B, Garcia P, Moro R F, Garrido N M, Marcos I S, Basabe P and Urones J G, Curr Org Synth., 2008, 5, 186-216.

9. Lauret C, Tetrahedron: Asymmetry, 2001, 12, 2359-2383.

10. Wielputz T, Sottmann T, Strey R, Schmidt F and Berkessel A, Chem Eur J., 2006, 12, 7565-7575.

11. Oh K and Ryu J, Tetrahedron Lett., 2008, 49, 1935-1938.

12. $\quad \mathrm{Lu}$ J, Xu Y H, Liu F and Loh T P, Tetrahedron Lett., 2008, 49, 6007.

13. Colonna S, Perdicchia D and Mauro E D, Tetrahedron: Asymmetry, 2009, 20, 1709-1714.

14. Wang H, Wang Z and Ding K, Tetrahedron Lett., 2009, 50(19), 2200.

15. Nagano M, Doi M, Kurihara M, Suemune H and Tanaka M, Org Lett., 2010, 12, 3564-3566,

16. Chen R, Qian C and de Vries J G, Tetrahedron, 2001, 57, 9837.

17. Liu X, Li Y, Wang G, Chai Z, Wu Y and Zhao G, Tetrahedron: Asymmetry, 2006, 17,750 .

18. Lange's Handbook of Chemistry, $13^{\text {th }}$ Edition, Ed., Dean J A, McGraw-Hill Book Company, New York, 1985, Chapter 7, 370.

19. Sharma L and Singh S, Indian J Chem., 1994, 33B, 851.

20. Sharma L and Singh S, Carbohydrate Res., 1995, 270(1), 43-49. 


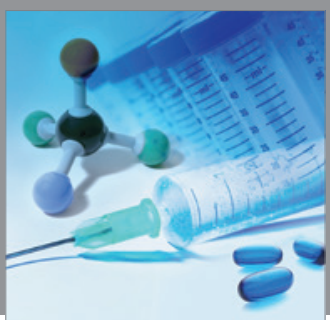

International Journal of

Medicinal Chemistry

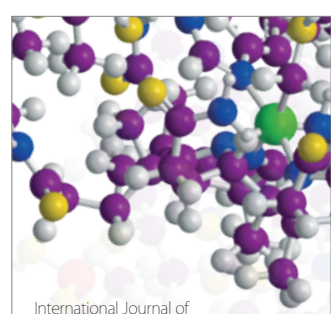

Carbohydrate Chemistry

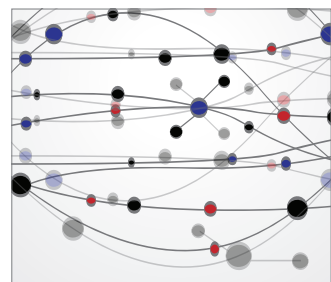

The Scientific World Journal
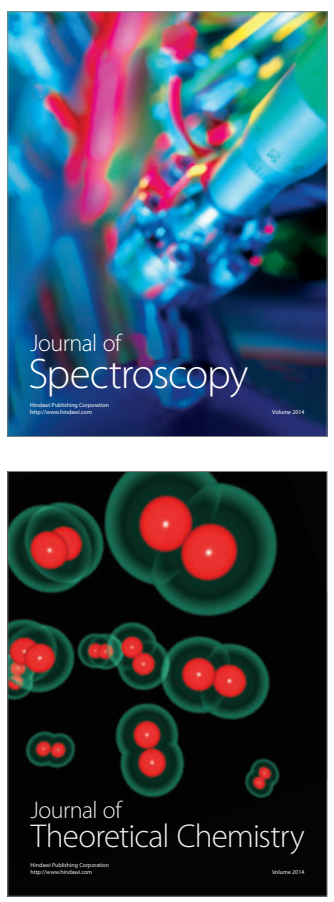
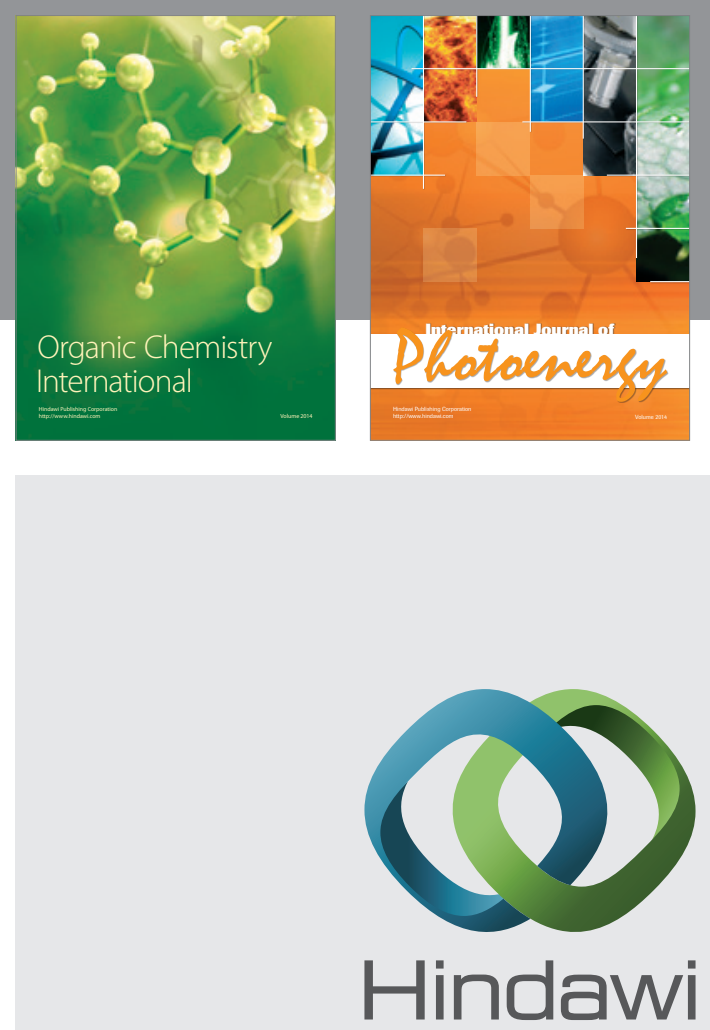

Submit your manuscripts at

http://www.hindawi.com
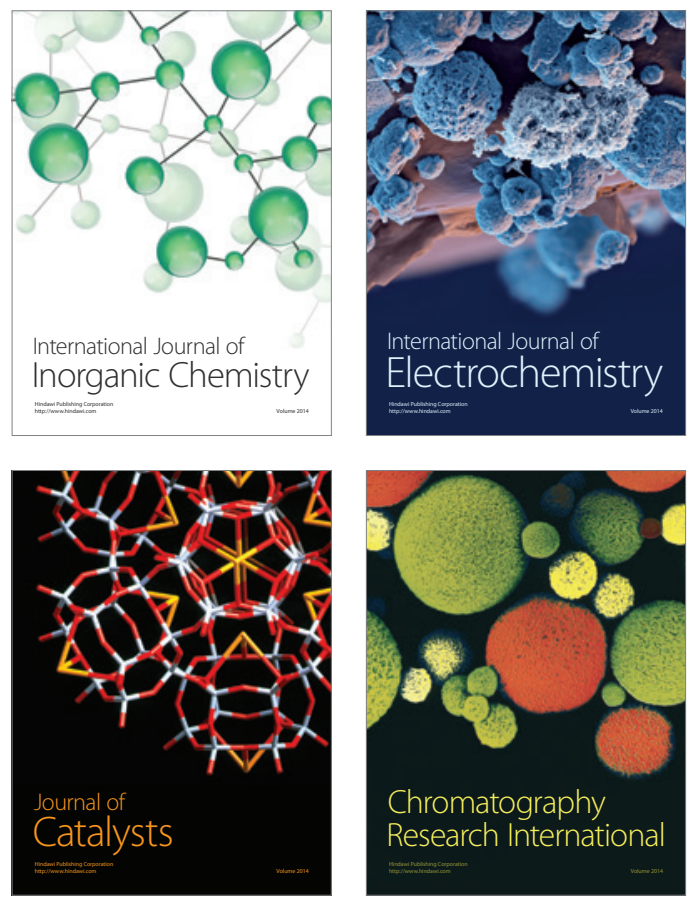
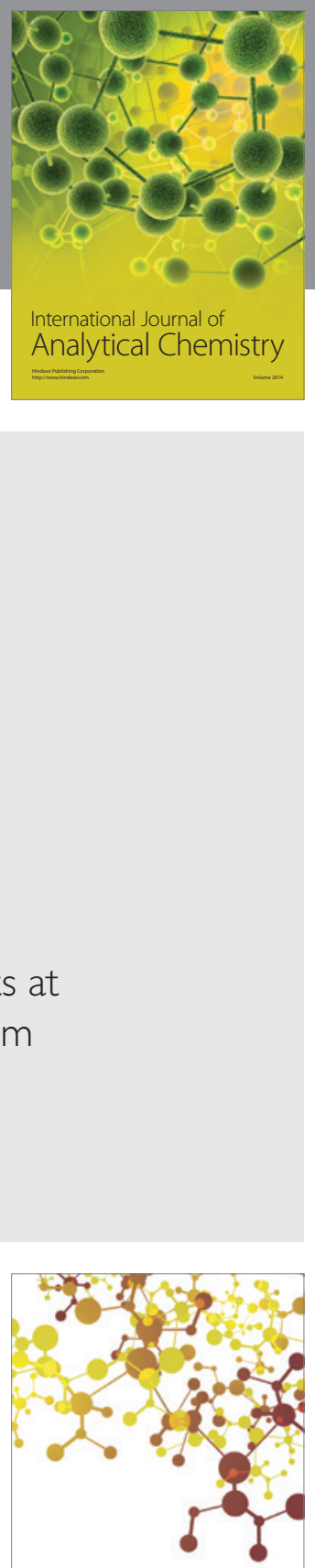

Journal of

Applied Chemistry
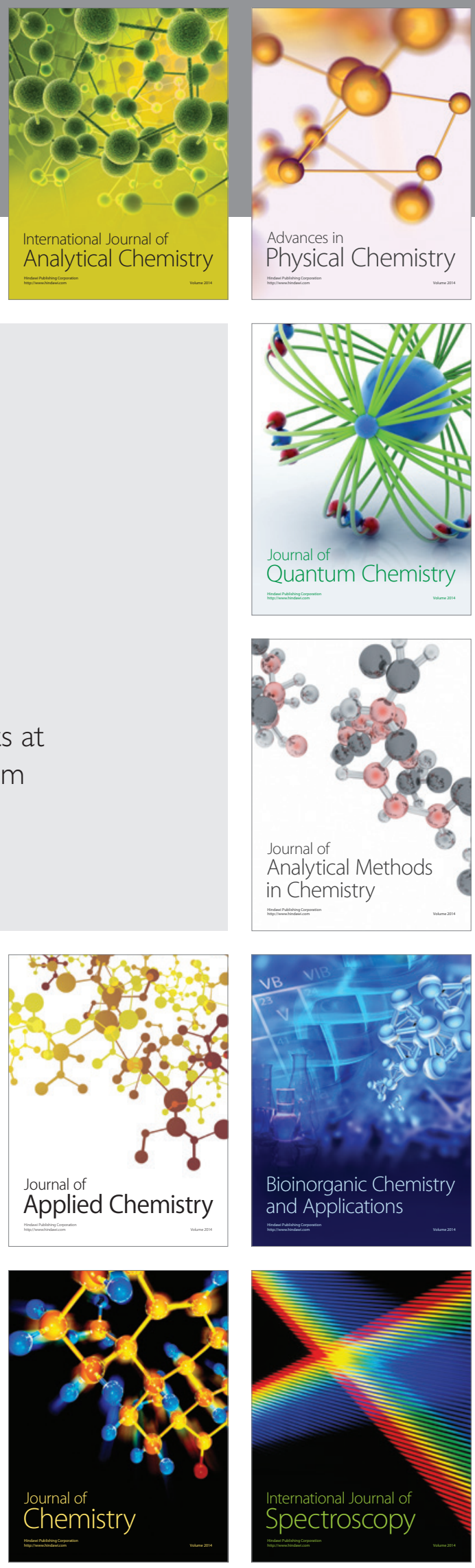